\title{
Reflexões sobre a avaliação da aprendizagem de alunos da modalidade Educação Especial na Educação Básica
}

\author{
Maria Sylvia Cardoso Carneiro*
}

\section{Resumo}

O presente texto faz algumas reflexões sobre a escolarização de alunos da modalidade educação especial na educação básica, focalizando questões sobre a avaliação da aprendizagem. As políticas educacionais em uma perspectiva inclusiva têm orientado os sistemas de ensino a desenvolver estratégias para o acolhimento de tais alunos no cotidiano escolar. Isso significa reconhecê-los como sujeitos de aprendizagem, levando em conta suas limitações, mas também suas possibilidades e principalmente suas especificidades e conseqüentes diferentes modos de aprender e de ensinar. Para que a educação especial se efetive como uma perspectiva inclusiva, as práticas pedagógicas escolares no âmbito da educação básica devem ser organizadas coletivamente na escola, preservando sempre o protagonismo do professor regente na condução dos processos de escolarização de todos os alunos. Porém, não é essa a dinâmica encontrada na maioria das escolas. A presença de estudantes com deficiência na escola do ensino regular tensiona ainda mais as discussões sobre a avaliação da aprendizagem, que será sempre tarefa do professor regente, daquele que planejou o processo de ensino/aprendizagem. Sem desconsiderar a importância de recursos específicos de acessibilidade ao espaço físico e à comunicação, além da adaptação de materiais pedagógicos às necessidades de cada aluno, é importante considerar que o processo de escolarização de tais sujeitos não pode se limitar à eliminação de barreiras, sejam elas físicas, comunicacionais, informacionais ou mesmo atitudinais. É fundamental que esteja nas prioridades das práticas pedagógicas escolares a apropriação, por todos os alunos, dos conhecimentos historicamente produzidos. Para que tal apropriação ocorra, é necessário um trabalho pedagógico articulado entre os diferentes profissionais da escola.

Palavras-chave: Modalidade Educação Especial; Avaliação da aprendizagem; Educação Básica.

\footnotetext{
* Professora Doutora da Universidade Federal de Santa Catarina (UFSC). Departamento de Estudos Especializados em Educação, Centro de Ciências da Educação, Florianópolis, Santa Catariana.
} 


\section{Reflections on the assessment of student learning in Special Education at Basic Education}

\section{Abstract}

This text reflects on special education student's accomplishment at basic education level, focusing on issues concerning the assessment of learning. Educational policies from an inclusive perspective have guided education systems to develop strategies with the purpose to include these students in school life. This means recognizing them as subjects of learning, taking into account their limitations, but also their possibilities and especially their peculiarities and the different ways of learning and teaching resulting from that. For special education to be effective as an inclusive perspective, pedagogical practices in school at basic education level should be organized collectively in school, always preserving the role of the coordinating teacher in conducting the schooling processes for all students. However, this is not the dynamics found in most schools. The presence of students with disabilities in regular education schools further tightens discussions on the evaluation of learning, which will always be a task assigned to the coordinating teacher, the one who planned the teaching/learning process. Without ignoring the importance of specific accessibility resources to physical space and communication, as well as of adapting teaching materials to the needs of each student, it is important to consider that the education process for these subjects cannot be limited to the elimination of barriers, whether physical, communicational, informational or attitudinal. It is essential that the priorities of school pedagogical practices include the ownership of the historically produced knowledge on behalf of all students. For such empowerment to materialize, it is necessary to perform a teaching work articulated among different school professionals.

Keywords: Special Education; Learning assessment; Basic Education.

Introdução

A escola tem sido identificada como espaço privilegiado de acesso ao conhecimento historicamente acumulado e socialmente valorizado. Embora o ingresso do Estado na educação escolar, a partir do século XVIII, tenha inaugurado a perspectiva da escolarização como direito, é apenas no século XX que passamos a ter políticas voltadas à universalização da escolarização. Tais políticas são 
resultantes da ação de forças e agentes sociais novos, como as classes sociais em luta, os Estados Nacionais e seus interesses em promover a escolarização, a aceleração das mudanças produtivas, a importância do conhecimento científico, a valorização da escola como promotora da educação de trabalhadores, a luta emancipatória da mulher, a descoberta da criança e da pesquisa psicológica. Nem por isto, a escola e a escolarização têm significado uma experiência exitosa e isenta de crise. (RIBEIRO, 2006, p. 54)

Considerando a diversidade de características dos alunos que a escola pública atende hoje, numa perspectiva anunciada como democrática, universalizante, "para todos", a proposta do presente texto é fazer algumas reflexões sobre a escolarização de estudantes da modalidade educação especial na educação básica, focalizando questões sobre a avaliação da aprendizagem. Até há algum tempo atrás a maioria desses alunos frequentava escolas e outras instituições de educação especial, ficando excluídos dos processos de escolarização nos níveis e etapas previstos para as diferentes faixas etárias. As discussões atuais sobre os limites e possibilidades de escolarização desses alunos em escolas do ensino regular podem contribuir para o enfrentamento de desafios vividos no cotidiano escolar e a conseqüente construção de práticas pedagógicas escolares que contemplem o respeito à diversidade humana.

Breves apontamentos históricos sobre a educação de pessoas com necessidades educacionais especiais

A educação de pessoas com deficiência e outras necessidades educacionais especiais (NEE) foi, durante muito tempo, tema tratado por especialistas na área, fossem eles pedagogos ou profissionais de outras áreas, como psicólogos, fonoaudiólogos, fisioterapeutas, terapeutas ocupacionais e médicos, compondo a chamada educação especial.

No Brasil, a segregação que marcou a educação dessas pessoas está associada a uma história de exclusão de grande parte das populações marginalizadas. Sob a influência de teorias racistas e de outras teorias de caráter liberal, o foco da responsabilidade pela evasão e reprovação escolares historicamente recai sobre os alunos, suas famílias, sua cultura (PATTO, 1993). Portanto, deste ponto de vista podemos considerar relevante o papel da educação especial, mesmo quando ela representava apenas uma alternativa de atendimento àqueles alunos considerados incapazes de freqüentar a escola comum. 
Alguns autores situam o início da educação especial a partir do surgimento, na Europa, no final do Século XVIII, de instituições especializadas na educação de surdos e cegos, destacando a expansão de oportunidades educacionais para as pessoas com deficiência.

Focalizando outros aspectos, Bueno (1993) mostra que a educação especial surge nas sociedades ocidentais industriais no Século XVIII, com a exigência do fim dos privilégios concedidos à nobreza e o direito a todos de ter acesso à escola. Portanto, a educação especial nasce juntamente com o modo de escolarização contemporâneo, que preconiza a escolarização como direito de todos os indivíduos:

[...] a história nos mostra que a Educação Especial não nasceu para dar oportunidade a crianças que, por anormalidades específicas, apresentavam dificuldades na escola regular. A Educação Especial nasceu voltada para a oferta de escolarização a crianças cujas anormalidades foram aprioristicamente determinadas como prejudiciais ou impeditivas para sua inserção em processos regulares de ensino. (Ibid, p. 27. Grifos do autor)

A expansão da educação especial no Brasil, principalmente na segunda metade do Século XX, embora tenha ampliado oportunidades educacionais a crianças que não teriam acesso ao ensino regular, incorporou uma população identificada como portadora de déficits na aprendizagem, em sua grande maioria provenientes das classes populares. Tal expansão pode ser compreendida, portanto, como expressão do processo de seletividade social promovido pela escola pública no Brasil. A partir da década de 60 , os altos índices de exclusão de alunos nas redes públicas já nas séries iniciais, seja pela evasão ou pela reprovação, ou ainda pela falta de oportunidade de acesso, eram explicados de diferentes maneiras, focalizando aspectos inerentes aos alunos e suas características, fossem elas orgânicas, emocionais ou culturais. Aqueles que fracassavam na escola eram vistos como portadores de algum tipo de problema que não competia mais à escola comum resolver.

Na década de 70 , são implantadas no Brasil as classes especiais nas escolas comuns, para o atendimento de alunos considerados deficientes mentais "leves" - aqueles que tinham alguma possibilidade de aprender os conteúdos escolares. Os estudos de Schneider (1974), Paschoalick (1981), Cunha (1988) e Machado (1994) mostram que tais classes acabaram servindo mais para atender alunos com problemas de aprendizagem e/ou de comportamento que já eram atendidos em classes comuns do que para 
integrar à escola alunos considerados deficientes mentais leves. Portanto, as classes especiais passaram a se constituir em um espaço de segregação, mesmo estando dentro das escolas comuns.

O movimento de integração, iniciado na Europa na década de 60 , propunha o acesso das pessoas com deficiência ao ensino em escolas regulares, pressupondo um diálogo entre a educação especial e a educação regular. Tal movimento ganha impulso no Brasil nos anos 80 , embora já se pudesse perceber forte influência dos princípios de normalização e integração nos documentos elaborados pelos órgãos oficiais de educação especial na esfera federal na década de 70 (MENDES, 1994). Tais princípios se traduziam, na prática, como segregação e exclusão, porém sua presença na legislação e nas discussões da área impulsionaram alguns inegáveis avanços.

Nos anos 90, mais fortemente a partir de 1994, com a divulgação da Declaração de Salamanca (UNESCO, 1994), o debate volta-se à inclusão de todas as crianças no ensino regular, independente de suas condições físicas, sociais, emocionais, lingüísticas ou culturais. Assim, passavam a ser necessárias mudanças significativas nas escolas para que estas pudessem cumprir seu papel de possibilitar o acesso ao conhecimento a todos os alunos, inclusive àqueles considerados com alguma deficiência ou com necessidades educacionais especiais.

Todo esse discurso em defesa da inclusão escolar dos alunos historicamente excluídos da escola vai sendo incorporado nos debates acadêmicos e embasa a atual legislação educacional brasileira, que prevê, dentre inúmeras ações de caráter inclusivo, algumas adequações necessárias nos sistemas de ensino para que a inclusão de alunos com NEE seja implementada. Assim, a partir da LDB (Lei n 9.394/96), a Política Nacional de Educação Especial na Perspectiva da Educação Inclusiva (BRASIL, 2008) define a educação especial como modalidade transversal aos níveis de ensino em todas as suas etapas, desde a educação infantil até a educação superior. No referido documento são retomados alguns marcos históricos da educação especial:

A educação especial se organizou tradicionalmente como atendimento educacional especializado substitutivo ao ensino comum, evidenciando diferentes compreensões, terminologias e modalidades que levaram a criação de instituições especializadas, escolas especiais e classes especiais. Essa organização, fundamentada no conceito de normalidade/anormalidade, determina formas de 
atendimento clínico terapêuticos fortemente ancorados nos testes psicométricos que definem, por meio de diagnósticos, as práticas escolares para os alunos com deficiência. (BRASIL, 2008, p. 6)

A educação especial em uma perspectiva inclusiva deixa de ser substitutiva ao ensino regular e assume caráter complementar e suplementar às atividades desenvolvidas na sala de aula comum. A complementação/ suplementação das atividades passa a ser responsabilidade do serviço denominado Atendimento Educacional Especializado (AEE), assumido por profissionais habilitados para atuar com alunos público alvo da educação especial:

O atendimento educacional especializado identifica, elabora e organiza recursos pedagógicos e de acessibilidade que eliminem as barreiras para a plena participação dos alunos, considerando as suas necessidades específicas. As atividades desenvolvidas no atendimento educacional especializado diferenciamse daquelas realizadas na sala de aula comum, não sendo substitutivas à escolarização. Esse atendimento complementa e/ou suplementa a formação dos alunos com vistas à autonomia e independência na escola e fora dela. (BRASIL, 2008, p. 16)

O carro-chefe da Política Nacional de Educação Especial é o investimento em salas multifuncionais, espaços equipados para atender a diferentes necessidades educacionais apresentadas por alunos com NEE. O que tem sido observado no cotidiano das escolas de ensino regular é que $\mathrm{o}$ atendimento às necessidades específicas dos alunos em tais salas não garante necessariamente sua participação efetiva como aluno nem o êxito nos processos de ensino/aprendizagem. Mesmo em escolas onde há a presença de profissional da educação especial e serviço de AEE atuante, o cotidiano escolar tem revelado a existência de inúmeros desafios. Destaco alguns deles a seguir, focalizando reflexões em torno dos processos de avaliação da aprendizagem dos alunos da modalidade educação especial na educação básica.

\section{Desafios vividos no cotidiano escolar}

As políticas educacionais em uma perspectiva inclusiva têm orientado os sistemas de ensino a desenvolver estratégias para o acolhimento de alunos com NEE no cotidiano escolar. Acolher tais alunos significa reconhecê-los como sujeitos de aprendizagem, levando em conta suas limitações, mas também suas possibilidades e principalmente suas especificidades e conseqüentes diferentes modos de aprender e de ensinar. 
Partindo do princípio de que todos podem aprender nas interações com os demais, ter em sala de aula um grupo de alunos com diferentes possibilidades exige que pensemos os processos de ensino/aprendizagem de forma coletiva, distinta do modelo que ainda encontramos na escola. A abordagem histórico-cultural aponta a heterogeneidade como característica de qualquer grupo humano, sendo fundamental para as interações em sala de aula. A multiplicidade de experiências, de trajetórias pessoais, de contextos familiares, de valores e níveis de desenvolvimento de cada membro do grupo possibilita trocas, confrontos, ajuda mútua e conseqüente ampliação das capacidades individuais e coletivas no cotidiano escolar.

Considerando essa argumentação, cabe perguntar: Como os sistemas de ensino, e mais especificamente as escolas, têm lidado com os processos de escolarização de alunos com NEE? Garantido o acesso, como tem lidado com as estratégias de ensino/aprendizagem, incluindo a avaliação da aprendizagem?

Carneiro, Garcia e Michels (2011) abordam aspectos das práticas pedagógicas escolares frente às exigências colocadas pelas políticas de inclusão. Focalizando as formas organizativas do trabalho pedagógico propostas para a educação de alunos com NEE, as pesquisadoras investigaram, entre outros aspectos, as concepções e as práticas que sustentam propostas consideradas como inclusivas. Tendo como campo empírico a Rede Municipal de Ensino de Florianópolis/SC, a qual atende ao critério de ter formulado uma proposta curricular de matiz inclusivo, as autoras chamam a atenção para a falta de articulação entre AEE e classe comum. Ou seja, o atendimento educacional especializado focaliza o aluno, seu diagnóstico e suas necessidades, faltando um diálogo entre educação regular e educação especial. Um diálogo que deveria ser pautado nos processos de ensino/aprendizagem, seja complementando/suplementando o trabalho pedagógico de sala de aula, seja auxiliando o professor regente a buscar alternativas para os impasses que se apresentam no cotidiano escolar. O estudo aponta que a ausência de estratégias sistemáticas de articulação entre o AEE e a sala regular abre caminho para ações no campo do improviso e da informalidade.

Os estudos de Michels \& Garcia $(2009,2010)$ têm indicado que embora a atual política de educação especial no Brasil favoreça a uma compreensão de modalidade complementar e transversal à educação básica e à educação superior, a ênfase está colocada sobre a criação de salas de recursos multifuncionais na educação básica e de núcleos de acessibilidade na educação superior, os quais se centram nos recursos a serem utilizados. Aspectos como as estratégias pedagógicas, a adaptação de atividades curriculares, os processos de ensino/aprendizagem dos 
estudantes com NEE, a avaliação da aprendizagem, não têm aparecido como foco nos documentos orientadores nem nos programas de formação continuada propostos e implementados pelo MEC. A ênfase nos recursos de acessibilidade a serem utilizados pelos profissionais especializados indicam uma perspectiva instrumental, secundarizando aspectos pedagógicos nas práticas da educação especial como modalidade complementar e transversal aos processos de escolarização:

A idéia de processo de ensino desapareceu do debate. Por outro lado, o termo aprendizagem é amplamente mencionado, mas definido como atividade individual para a qual devem ser organizados ambientes e recursos além da composição de grupos heterogêneos. (MICHELS \& GARCIA, 2010, p. 15)

Discutindo outros aspectos acerca da inclusão escolar de alunos com NEE, políticas públicas e práticas pedagógicas, Ferreira \& Ferreira (2004) chamam a atenção também para o percurso histórico de constituição da educação especial, cujas práticas educativas, mesmo as mais recentes, indicam que:

na aparência das formulações curriculares os objetivos gerais identificam-se com os da educação regular, mas ao olharmos os objetivos desenvolvidos em sala de aula, estes se afastam da área acadêmica ou escolar, ficando mais centrados em atividades de natureza prática, repetitivas e de pouco significado cultural, bastante distante daquilo que está proposto para todos os alunos na escola regular. (FERREIRA \& FERREIRA, 2004, p. 42)

Tal distanciamento é percebido também pelos próprios alunos público-alvo da educação especial, na medida em que eles ingressam na escola regular com expectativas que nem sempre são contempladas em seu processo de escolarização. Eles desejam participar de todas as atividades escolares, incluindo a participação nas aulas e realização das tarefas propostas a todos os alunos, as saídas de estudos, gincanas, olimpíadas e tudo mais que compõe o cotidiano escolar. Mas nem sempre a escola consegue lhes garantir o acesso adequado.

Uma outra questão que tem gerado controvérsias nos remete a uma das estratégias que as escolas em geral têm utilizado para a efetivação de práticas pedagógicas inclusivas na presença de alunos com NEE: a contratação de um profissional que auxilie o professor no cotidiano escolar. Ocorre que na prática esse profissional é quem se encarrega do aluno com NEE. Ou seja, esse profissional acaba sendo identificado na comunidade 
escolar como o professor ou auxiliar do aluno com NEE. Assim, o aluno tem garantida sua matrícula e sua presença na sala de aula, mas pouco interage com os colegas e professores. É importante destacar que a Política Nacional de Educação Especial na perspectiva da Educação Inclusiva (BRASIL, 2008) prevê a contratação de monitores ou cuidadores, sem referência explícita a atribuições pedagógicas:

Cabe aos sistemas de ensino, ao organizar a educação especial na perspectiva da educação inclusiva, disponibilizar as funções de instrutor, tradutor/intérprete de Libras e guia intérprete, bem como de monitor ou cuidador aos alunos com necessidade de apoio nas atividades de higiene, alimentação, locomoção, entre outras que exijam auxílio constante no cotidiano escolar. (BRASIL, 2008, p. 17)

Sobre essas questões acerca da atuação do profissional de apoio ao professor, o trabalho de Martins (2010) apresenta contribuições importantes. Ao analisar documentos nacionais e de redes municipais de ensino da Regional Grande Florianópolis , a autora encontrou diferentes nomenclaturas e atribuições para o profissional da educação especial que atua em salas de aula onde há alunos com NEE. Quanto às nomenclaturas, em um universo de 12 municípios, foram encontradas em oito deles as seguintes: segundo professor, professor, auxiliar de ensino em educação especial, professor 2, professor mediador, auxiliar de ensino para aluno com deficiência. Quanto às atribuições, percebe-se igualmente uma variação que vai desde atribuições pedagógicas como planejamento conjunto e co-regência até a auxílio na higiene, locomoção, alimentação, atividades motoras, comunicação, interação com os demais.

Outro desafio vivido em diferentes contextos escolares são os movimentos de resistência aos processos de inclusão de alunos com NEE por parte de alguns educadores. Mesmo se considerarmos a sinalização da política educacional vigente para que as práticas pedagógicas do AEE sejam articuladas àquelas desenvolvidas pelos professores das salas regulares, a educação especial ainda é vista como um sistema paralelo, que hoje estaria a serviço da escola regular dando conta das necessidades específicas dos alunos historicamente atendidos em instituições especializadas.

Ao lado de movimentos de resistência, encontramos também movimentos de abertura ao acolhimento das diferenças por parte de alguns educadores. A diversificação de experiências com alunos que apresentam necessidades muito específicas tem impulsionado os educadores a buscar diferentes estratégias, informações, apoio as suas dúvidas e inseguranças. Tais experiências, quando vividas coletivamente na escola com o apoio de 
diferentes grupos (profissionais de educação especial da própria escola ou da rede de ensino, consultorias, trabalhos colaborativos de pesquisa-ação, formação continuada) contribuem para produzir um sentimento de maior competência profissional nos educadores. Tais movimentos podem resgatar no professor as suas possibilidades de educar todos os alunos.

\section{A presença de alunos da educação especial no ensino regular}

Quem são os alunos da modalidade educação especial? Que desafios apresentam à escola? Eles são capazes de aprender os conteúdos escolares?

Estudos de diferentes trajetórias de escolarização de alunos com deficiência demonstram as inúmeras barreiras vividas por esses alunos, suas famílias e professores (CAIADO, 2003; VASQUES, 2003; ALBINO, 2008; CARNEIRO, 2008). Por mais difícil que seja para tais alunos viver percursos escolares em instituições de ensino regular, é importante destacar que a escolarização é um importante elemento constitutivo do desenvolvimento de todos os alunos, inclusive daqueles com deficiência. De acordo com a abordagem histórico-cultural, mesmo com diferentes limitações no desenvolvimento, seja do ponto de vista motor, sensorial, intelectual, todos os sujeitos se constituem nas relações sociais. Portanto, é na escola regular que eles tem maiores chances de aprender conteúdos de diferentes níveis de complexidade, reafirmando a idéia de que o aprendizado impulsiona o desenvolvimento humano (VIGOSTSKI, 2003).

Mesmo com a divulgação de tais estudos, alguns apontando aspectos favoráveis nos processos de aprendizagem de alunos com deficiência, outros mostrando o quando a escola ainda se sente despreparada para trabalhar com tais alunos, há muitas dúvidas, por parte dos professores, acerca das possibilidades de escolarização desses sujeitos.

\section{Possibilidades de enfrentamento dos desafios, incluindo a avaliação} da aprendizagem

Para que a educação especial se efetive como uma perspectiva inclusiva, as práticas pedagógicas escolares no âmbito da educação básica devem ser organizadas coletivamente na escola, preservando sempre o protagonismo do professor regente na condução dos processos de escolarização de todos os alunos. Os profissionais da educação especial que atuam na escola (sejam eles os professores que atuam no atendimento educacional especializado ou profissionais de apoio ao professor em sala de aula) precisam manter o foco do seu trabalho no processo de escolarização 
dos alunos da modalidade educação especial, apoiando os professores e demais profissionais da escola, sem contudo substituí-los nas tarefas que Ihes cabem.

Ensinar é a tarefa central do professor. Ensinar a todos os alunos, sem discriminação. Ensinar a partir de um plano de ensino que considere a presença de todos os alunos, com suas especificidades Em um plano de ensino, espera-se que estejam contemplados, pelo menos: os objetivos a serem alcançados; os conteúdos a serem trabalhados; a metodologia a ser utilizada, incluindo aqui as estratégias de ensino e a proposta de avaliação. Compreendida desta forma, a avaliação é um momento do processo de ensino/ aprendizagem. Mas há outros olhares sobre a avaliação da aprendizagem.

Trata-se de um tema polêmico, com múltiplas compreensões, sendo que a ideia que considero a mais problemática é a da avaliação como um momento em si, descolado do processo de ensino-aprendizagem. Tal compreensão pressupõe que o objetivo de avaliar é verificar os conteúdos aprendidos, expressos por notas ou conceitos padronizados. Nesse caso, a avaliação seria a finalização do processo ensino/aprendizagem. Ou seja, o ciclo da aprendizagem seria: o estudante entra em contato com os conteúdos, pratica tais conteúdos através de exercícios e depois demonstra ao professor se aprendeu o que foi ensinado.

Em uma outra perspectiva, Esteban (2010) define a avaliação da aprendizagem como:

Processo intencional e sistemático de coleta, análise e interpretação de informações sobre conhecimentos, capacidades, atitudes e processos cognitivos dos sujeitos, em que se estima o valor ou mérito desses processos e/ou resultados, com a finalidade de produzir conhecimento para orientar a tomada de decisões relativas ao processo educacional ou a políticas educacionais. Diretamente relacionada à dinâmica pedagógica, entrelaça-se a questões de poder, mantendo fortes vínculos com demandas sociais e com políticas públicas. Termo polissêmico, seu estudo, formulação e prática estão em permanente tensão, traz marcas dos diálogos que estabelece com diferentes contextos, ideologias, culturas e perspectivas teóricas.

A autora destaca que as práticas avaliativas formais conservam a medida como elemento nuclear, embora algumas de suas versões já expressem reflexões sobre sua dimensão qualitativa. Tais práticas, ao priorizar aspectos quantitativos, dão pouca visibilidade às aprendizagens 
efetivas. Portanto, pouco contribuem para detectar o que foi de fato aprendido e o que se constitui como dificuldade a ser superada através de intervenções pedagógicas planejadas para tal.

Se considerarmos que o objetivo central da avaliação da aprendizagem é produzir conhecimento para orientar a tomada de decisões relativas ao processo educacional, os aspectos quantitativos, tais como a nota, ficam num plano secundário. Retoma-se o papel do professor, o de ensinar, e a avaliação pode ser vista como um processo crítico e reflexivo, cuja função é impulsionar novas aprendizagens.

E em relação aos alunos com deficiência, como o professor deve pensar sua avaliação? A presença de estudantes com deficiência na escola do ensino regular tensiona ainda mais as discussões sobre a avaliação da aprendizagem. Os professores em geral, sem uma formação para atender as necessidades específicas dos alunos com deficiência, consideramse incapazes de responder a esta e a outras questões que se relacionam à escolarização de tais alunos. É comum os professores acreditarem que a avaliação deve ser sempre diferenciada, adaptada, ou até mesmo facilitada para os estudantes com deficiência. Ou seja, o foco acaba sendo a verificação da aprendizagem, sem contudo focalizar as estratégias que foram propostas para o aluno aprender. Portanto, o que precisa ser adaptado são os instrumentos de avaliação, da mesma forma como outros recursos pedagógicos utilizados para o ensino de conteúdos de diferentes áreas do conhecimento. Tais instrumentos devem ser adequados às possibilidades de comunicação dos alunos. Assim, um aluno cego deve ter seus instrumentos de avaliação da aprendizagem adequados à sua condição sensorial diferenciada em relação aos demais. As adequações vão depender da trajetória escolar de cada aluno. Atividades em Braille para aqueles que utilizam tal sistema de escrita, utilização de computador com programas de voz para os que se apropriam do conhecimento através desse recurso. Além disso, descrição de imagens e apresentação de materiais em relevo, para que tais estudantes tenham acesso aos conhecimentos que circulam na escola.

Alunos com deficiência intelectual que não se apropriaram suficientemente da escrita podem ter seus instrumentos de avaliação adaptados, com o apoio de imagens, de informações adicionais, ou mesmo o apoio de um ledor. Podem também se beneficiar do processo de avaliação quando este é dividido em etapas (por exemplo, provas e trabalhos parcelados, com maior prazo para sua realização). 
Da mesma forma, alunos com deficiência física com comprometimentos na escrita também podem ser avaliados com o auxílio de um profissional de apoio, que pode escrever o que o estudante dita. Ou, ainda, o apoio pode ser através de tecnologias assistivas, que permitam uma comunicação (oral ou escrita) adequada.

Portanto, a avaliação da aprendizagem será sempre tarefa do professor regente, daquele que planejou o processo de ensino/aprendizagem. Tal tarefa pode ser compartilhada com outro profissional, seja ele um professor especializado, um profissional de apoio ou mesmo um profissional de fora da escola, aumentando as chances de êxito na busca das adequações necessárias para o processo de avaliação.

A presença de alunos com NEE com certeza mobiliza a escola e mais intensamente as turmas desses alunos. As necessidades específicas apresentadas por eles geram a necessidade de flexibilizar tempos, espaços e práticas pedagógicas, configurando novas dinâmicas de organização escolar. Contudo, tais flexibilizações devem ser propostas com a perspectiva de garantir processos de ensino/aprendizagem. As mudanças necessárias tendem a ser significadas pela escola como dificuldades ou obstáculos, tais como:

- a inadequação de espaços físicos, referentes a aspectos arquitetônicos em desacordo com o denominado desenho universal ;

- entraves nos processos de comunicação devido à utilização - por alguns alunos - de códigos lingüísticos distintos dos usuais (Libras, Braille, recursos de comunicação alternativa);

- diferentes dificuldades dos professores em lidar com situações do cotidiano escolar que demandariam uma reorganização das dinâmicas das práticas pedagógicas.

São legítimas as dificuldades e angústias vividas pelos professores diante de situações como ter um aluno que não enxerga ou que não fala. Ou na relação pedagógica com um aluno que não escuta, ou que tem limitações motoras. Ou ainda, lidar em sala de aula com quem tem uma dinâmica diferente da maioria dos alunos, com limitações nos modos de responder satisfatoriamente às atividades propostas. Tais dificuldades podem ser enfrentadas com apoio de outros profissionais da escola. Lamentavelmente, ainda se espera que o professor regente assuma individualmente a responsabilidade pelos processos de ensino/aprendizagem de todos os seus alunos. A realidade em diferentes redes de ensino tem mostrado que ainda recai sobre os professores que tem em sua turma alunos com necessidades 
educacionais especiais a tarefa de buscar individualmente novas possibilidades de atuação pedagógica. Mesmo quando há um profissional de apoio em sala ou um professor especializado que atenda a alguns dos alunos nos serviços de AEE, percebe-se que o foco da atuação desses profissionais está muito mais voltado para recursos específicos de acessibilidade ao espaço físico e à comunicação, além da adaptação de materiais pedagógicos às necessidades de cada aluno.

Sem desconsiderar a importância de tais aspectos no processo de inclusão escolar de alunos com necessidades especiais, é importante considerar que o processo de escolarização de tais sujeitos não pode se limitar à eliminação de barreiras, sejam elas físicas, comunicacionais, informacionais ou mesmo atitudinais. É fundamental que se coloque no horizonte de prioridades das práticas pedagógicas escolares a apropriação, por todos os alunos, dos conhecimentos historicamente produzidos. Para que tal apropriação ocorra, é necessário um trabalho pedagógico articulado entre os diferentes profissionais da escola.

\section{Referências}

BRASIL. Lei n. 9.394, de 20 de dezembro de 1996. Estabelece as diretrizes e bases da educação nacional. Diário Oficial da União, Brasília, 23 dez. 1996.

Conselho Nacional de Educação. Câmara de Educação Básica. Resolução CNE/CEB n. 4, de 2 de outubro de 2009. Institui Diretrizes Operacionais para o Atendimento Educacional Especializado na Educação Básica, modalidade Educação Especial. Diário Oficial da União, Brasília, 24 set. 2009.

Conselho Nacional de Educação. Câmara de Educação Básica. Resolução CNE/CEB n.4/2010 - Define Diretrizes Curriculares Nacionais Gerais para a Educação Básica. Disponível em: <http://portal.mec.gov.br/ index.php?option=com_content\&view=article\&id=12992: diretrizes-para-aeducacao-basica\&catid=323> Acesso em: 24 out. 2012.

Secretaria de Educação Especial. Política Nacional de Educação Especial na Perspectiva da Educação Inclusiva. Brasília, 2008. Disponível em: <http://portal.mec.gov.br>. Acesso em: 17 abr. 2011.

BUENO. J. G. S. A educação do deficiente auditivo no Brasil: situação atual e perspectivas. Em Aberto, Brasília, (60), p. 25-36, out./dez. 1993.

CAIADO, K. R. M. O Aluno Deficiente Visual na Escola: lembranças e depoimentos Campinas: Autores Associados, PUC, 2003. 
CARNEIRO, M. S. C. Adultos com síndrome de Down: a deficiência mental como produção social. Campinas: Papirus, 2008.

CARNEIRO, M. S. C., GARCIA, R. M. C.; MICHELS, M. H. Implicações da diversificação na dinâmica das salas multimeios na rede municipal de Florianópolis: o caráter conservador da perspectiva inclusiva na educação especial. In: VI SEMINÁRIO NACIONAL DE PESQUISA EM EDUCAÇÃO ESPECIAL, 6., 2011, Serra/ES. Anais...

CUNHA, B. B. Classes de educação especial para deficientes mentais: intenção e realidade. 1988. Dissertação (Mestrado em Psicologia) - Instituto de Psicologia da USP - São Paulo, 1988.

ESTEBAN, M. T. Avaliação da aprendizagem. In: OLIVEIRA, D. A.; DUARTE, A. M. C.; VIEIRA, L. M. F. Dicionário: trabalho, profissão e condição docente. Belo Horizonte : UFMG/Faculdade de Educação, 2010. CDROM.

FERREIRA M. C. C.; FERREIRA, J. R. Sobre inclusão, políticas públicas e práticas pedagógicas. In: GÓES, M. C. R.; LAPLANE, A. L. F. Políticas e práticas de educação inclusiva. Campinas: Autores Associados, 2004. p. 21-48.

JESUS, D. M. O que nos impulsiona a pensar a pesquisa-ação colaborativocrítica como possibilidade de instituição de práticas educacionais mais inclusivas? In: BAPTISTA, C.R. et. al. (Orgs.). Educação Especial: diálogo e pluralidade. Porto Alegre : Mediação, 2008. p. 139-159.

MACHADO, A. M. Crianças de classe especial: efeitos do encontro da saúde com a educação. São Paulo: Casa do Psicólogo, 1994.

MENDES, E. G. Integração escolar: reflexões sobre a experiência de Santa Catarina. Integração, Brasília, Secretaria de Educação Especial - MEC. n. 12, p. 5-16, 1994.

MARTINS, S. M. As políticas de educação especial na perspectiva inclusiva no Brasil e o trabalho nas classes com crianças com necessidades educacionais especiais nos municípios pertencentes à Regional Grande Florianópolis. In: VIII ENCONTRO DE PESQUISA EM EDUCAÇÃO DA REGIÃO SUL, 8., 2010, Londrina/PR. Anais.

MICHELS, M. H.; GARCIA, R. M. C. A reorganização de redes municipais de ensino na perspectiva da educação inclusiva em Santa Catarina: formas organizativas do trabalho pedagógico e formação de professores. Relatório de Pesquisa. Universidade Federal de Santa Catarina. Florianópolis/ SC 2009. 
MICHELS, M. H.; GARCIA, R. M. C. Políticas públicas de educação especial e escolarização de sujeitos com deficiência. Trabalho apresentado na I Reunião Integrada de Pesquisa, realizado na Universidade Estadual de Londrina/PR de 11 a 13 de ago. 2010.

NUNES, L. R. O. P.; SOBRINHO, F. P. N. Acessibilidade. In: BAPTISTA, C. R. et. al. (Orgs.). Educação especial: diálogo e pluralidade. Porto Alegre: Mediação, 2008. p. 269-279.

PASCHOALICK, W. Análise do processo de encaminhamento de crianças das classes especiais para deficientes mentais. 1981. Dissertação (Mestrado em Educação) - PUC/SP, São Paulo, 1981.

PATTO, M. H. S. A produção do fracasso escolar: histórias de submissão e rebeldia. São Paulo : T.A. Queiroz, 1993.

PEREIRA, O. Princípios de normalização e integração na educação dos excepcionais. In: PEREIRA, Olívia et al. Educação especial: atuais desafios. Rio de Janeiro: Interamericana, 1980. p. 1-14.

RIBEIRO, J. A. R. Momentos históricos da escolarização. In: BAPTISTA, C. R. (Org.). Inclusão e escolarização: múltiplas perspectivas. Porto Alegre: Mediação, 2006. p. 53-71.

SANTOS, R. A. Processos de escolarização e deficiência : trajetórias escolares singulares de ex-alunos de classe especial para deficientes mentais. In: BUENO, J. G. S. et al. (Orgs.). Deficiência e escolarização: novas perspectivas de análise. Araraquara: Junqueira \& Marin; Brasília: CAPES, 2008, p. 415-467.

SCHNEIDER, D. W. Classes esquecidas: os alunos excepcionais do estado da Guanabara., 1974. Dissertação (Mestrado em Antropologia Social) UFRJ, Rio de Janeiro, 1974.

UNESCO. Coordenadoria para a Integração da Pessoa Portadora de Deficiência. Declaração de Salamanca e Linha de Ação sobre necessidades educativas especiais. Brasília, 1994.

VASQUES, C. K. Um coelho branco sobre a neve: estudo sobre a escolarização de sujeitos com psicose infantil. 2003. Dissertação (Mestrado em Educação) - Faculdade de Educação, Universidade Federal do Rio Grande do Sul, Porto Alegre.

VIGOTSKI, L. S. Aprendizagem e desenvolvimento intelectual na idade escolar. In: VIGOTSKI, L.S.; LURIA A.R.; LEONTIEV, A.N. Linguagem, desenvolvimento e aprendizagem. São Paulo : Ícone. 


\section{Notas}

1 A Resolução CNE/CEB n 4/2010 define em seu Art. 29: "A Educação Especial, como modalidade transversal a todos os níveis, etapas e modalidades de ensino, é parte integrante da educação regular, devendo ser prevista no projeto político-pedagógico da unidade escolar." No mesmo artigo, $\S 1^{\circ}$ define também o público-alvo da modalidade Educação Especial: estudantes com deficiência, transtornos globais do desenvolvimento e altas habilidades/superdotação.

${ }^{2}$ Utilizo neste trabalho o termo necessidades educacionais especiais (NEE) para referir-me a diferentes condições de alunos público-alvo da modalidade educação especial: alunos com deficiência, transtornos globais do desenvolvimento ou altas habilidades/superdotação, de acordo com os documentos Política Nacional de Educação Especial na perspectiva da Educação Inclusiva (BRASIL, 2008) e Resolução CNE/CEB 04/2010 - Define Diretrizes Curriculares Nacionais Gerais para a Educação Básica (BRASIL, 2010).

${ }^{3}$ Sobre os princípios de normalização e integração, ver a obra de Pereira (1980).

${ }^{4}$ Recursos de acessibilidade na educação são aqueles que "asseguram condições de acesso ao currículo dos alunos com deficiência ou mobilidade reduzida, promovendo a utilização dos materiais didáticos e

pedagógicos, dos espaços, dos mobiliários e equipamentos, dos sistemas de comunicação e informação, dos transportes e dos demais serviços" (BRASIL, 2009).

${ }^{5}$ Segundo a autora, a denominação Regional Grande Florianópolis é utilizada pela Secretaria de Educação do Estado de Santa Catarina como forma de agrupar os municípios próximos à capital do Estado.

${ }^{6}$ Sobre pesquisa-ação e formação continuada de professores na perspectiva da inclusão escolar de alunos com NEE, ver JESUS , D.M. (2008).

7 "Desenho universal pode ser conceituado como um conjunto de idéias, procedimentos e práticas geradores de espaços, ambientes, serviços, produtos e tecnologias acessíveis, utilizáveis de forma igualitária, segura e autônoma por todas as pessoas, na maior extensão possível, independentemente das suas capacidades, habilidades e medidas antropométricas, e sem que tenham que ser adaptados ou readaptados especificamente para cada um" (CORREIA \& CORREIA, apud NUNES \& SOBRINHO, 2008, p. 270).

\section{Correspondência}

Maria Sylvia Cardoso Carneiro - Universidade Federal de Santa Catarina, Centro de Ciências da Educação. Campus Universitário - Bloco B. Trindade - Caixa-postal: 476 - CEP 88040-900 - Florianopolis, Santa Catarina.

E-mail: sylvia@ced.ufsc.br

Recebido em 20 de julho de 2012

Aprovado em 26 de outubro de 2012 